\title{
Advising patients about obtaining genomic profiles
}

\author{
Donna T. Chen, MD, MPH
}

Lois L. Shepherd, JD

\begin{abstract}
Summary
Neurologists, as all physicians, should begin to familiarize themselves with elements of genomic medicine to help their patients navigate the promises and pitfalls of obtaining genomic profiles. The neurologist should encourage a realistic assessment of the patient's expectations regarding the genetic information to be provided and apprise the patient of the challenges involved in obtaining interpretable, clinically useful information. A review of risks of obtaining genomic information is equally important. Discrimination, loss of privacy, receiving inaccurate or unwanted information, and learning information that may create obligations to disclose to others are all possibilities. As genomic research and direct-toconsumer opportunities to obtain genomic information expand, reliance on personal physicians for ethical advice based on current advancements in genomic profiling should be anticipated.
\end{abstract}

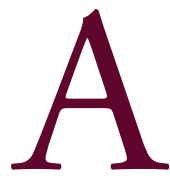

49-year old Chinese American woman with chronic headache and her husband consider enrollment in a study investigating genetic and environmental contributions to headache. The couple are curious about their genomic profiles and wonder if this information might help them make better health care decisionsfor example, by explaining why she has headaches and whether he is at high risk for stroke since his father had stroke at an early age. The pair want to contribute to research and are excited they could get this information free from the study, yet remain undecided. Based in part on recommendations found on direct-to-consumer Web sites to discuss

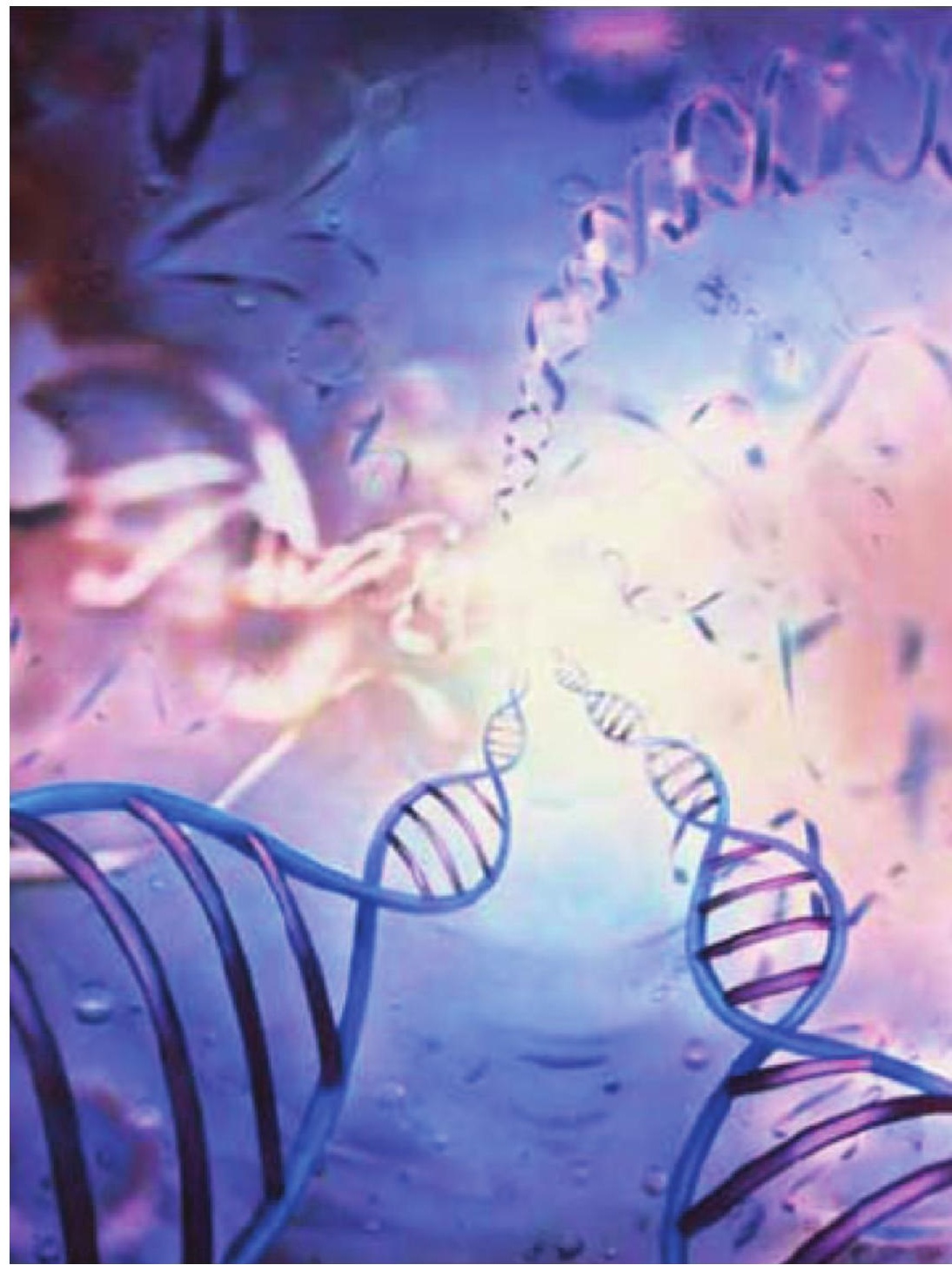

Center for Biomedical Ethics and Humanities (DTC, LLS), Department of Public Health Sciences (DTC, LLS), Department of Psychiatry and Neurobehavioral Sciences (DTC), and School of Law (LLS), Center for Biomedical Ethics and Humanities, University of Virginia Health System, Charlottesville.

Correspondence to: $\mathrm{dtc} 6 \mathrm{k} @$ virginia.edu 


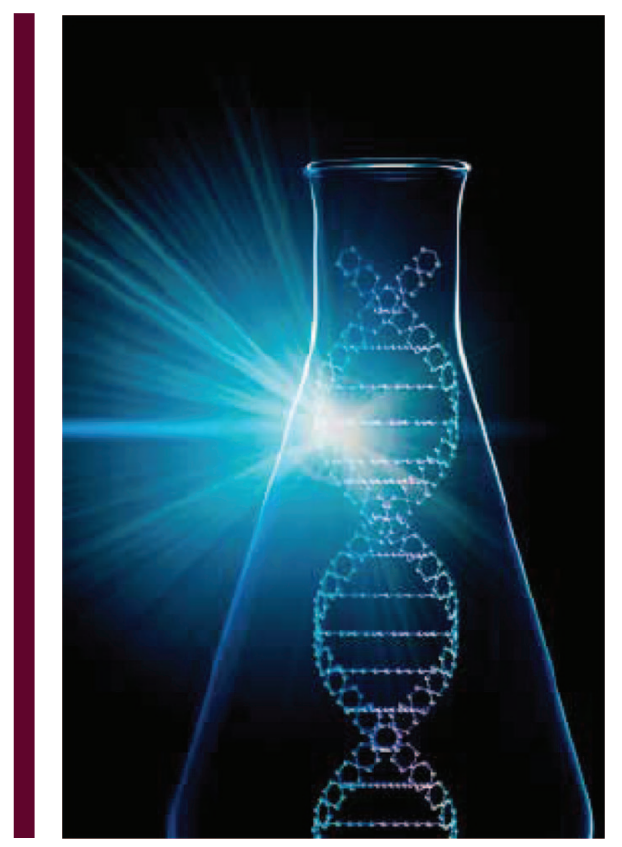

\section{Use of genomic results} to guide medication selection and dosingpharmacogenomics-long heralded as the likely first widespread application of the new genomics for screening, is beginning to show clinical utility.

genomic testing with a physician, and with the blessing of the study investigators, the couple make an appointment with a trusted neurologist, whom they have known for a long time.

\section{DISCUSSION}

Neurologists presented with a patient asking for advice about obtaining a genomic profile might be tempted to respond that this is outside their scope of practice. Some may suggest referral to a genetics expert, but such experts are few and far between. ${ }^{1}$ While potentially intimidating, this scenario presents an important opportunity to fulfill the physician's duties of trusted advisor. Indeed, while few physicians currently recommend genomic profiling, many direct-to-consumer testing companies suggest involving personal physicians to help interpret results and their implications, and the Food and Drug Administration (FDA) may soon require some form of physician involvement, though the particulars are largely undecided. ${ }^{2}$ Similarly, researchers and ethicists who suggest providing individualized genomic information to research participants also recommend involving personal physicians or genetic counselors, or both. ${ }^{3,4}$ Thus, it is inevitable that all physicians, including neurologists, will sooner or later face the request for advice about interpreting genomic information, and whether to obtain it in the first place. Accordingly, they should begin to develop competencies in relation to the new genomics, including the ability to provide basic, ethically sound advice about obtaining genomic information, whether in the context of a research study or otherwise. ${ }^{1,5}$

Here, the neurologist should cover at least the following topics with the patient (table 1): 1) her hopes and beliefs about obtaining her genomic profile and her expectations for this doctor with respect to reviewing her genomic information, 2) some important risks to obtaining genomic information that she may not have considered, and 3) whether the research study she is considering is designed to provide what she is looking for and what her participation in research might involve. In what follows, we discuss important aspects of the neurologist's coverage of these topics, including some basic information about the current status of genomic profiling, the disclosure and confidentiality norms and privacy rules applicable to genetic information, and the regulations governing research.

\section{Hopes and beliefs about personalized genomic medicine: Promise and limitations}

Individuals are beginning to express interest in their genomes. Some purchase direct-toconsumer profiles over the Internet; others gain access through a genetic research study that 
Table 1 Advising patients

\begin{tabular}{|c|c|}
\hline Discussion topic & Points to consider \\
\hline \multirow{2}{*}{$\begin{array}{l}\text { Benefits of obtaining } \\
\text { genomic profile } \\
\text { information }\end{array}$} & $\begin{array}{l}\text { - Inquiring about the patient's perception of benefits to } \\
\text { obtaining genomic information }\end{array}$ \\
\hline & $\begin{array}{l}\text { - Counteracting media and direct-to-consumer hype by } \\
\text { clarifying the current state of scientific knowledge and } \\
\text { clinical utility }\end{array}$ \\
\hline \multirow[t]{2}{*}{$\begin{array}{l}\text { Risks of obtaining genomic } \\
\text { profile information }\end{array}$} & $\begin{array}{l}\text { - Discussing the possibility of discrimination and loss of } \\
\text { privacy }\end{array}$ \\
\hline & $\begin{array}{l}\text { - Cautioning the patient about receiving inaccurate or } \\
\text { unwanted information or information that may create } \\
\text { obligations to disclose to others }\end{array}$ \\
\hline $\begin{array}{l}\text { Physician's receipt and use } \\
\text { of genomic information in } \\
\text { patient care }\end{array}$ & $\begin{array}{l}\text { - Reaching mutual understanding about whether the } \\
\text { genomic profile will be placed in the medical record } \\
\text { and how the physician will consult the genomic } \\
\text { information }\end{array}$ \\
\hline \multirow[t]{3}{*}{ Research study } & $\begin{array}{l}\text { - Learning about the type and form of information that } \\
\text { will be provided by researchers to the patient and } \\
\text { discussing its utility with the patient }\end{array}$ \\
\hline & $\begin{array}{l}\text { - Explaining the possibility that the patient may lose } \\
\text { control over de-identified samples/information as } \\
\text { future studies access them without the patient's } \\
\text { knowledge or consent }\end{array}$ \\
\hline & $\begin{array}{l}\text { - Pointing out reasons, besides personal benefit, why } \\
\text { the patient may want to participate in research }\end{array}$ \\
\hline
\end{tabular}

returns individualized results. While taking proactive steps to obtain genomic information is still restricted to "early adopters," studies of these early-adopting individuals across different countries suggest that in addition to satisfying their curiosity, these individuals believe they can, and will, use this information to improve their health. ${ }^{6,7}$ And while few discuss it with their physicians a priori, the vast majority (between $80 \%$ and $90 \%$ ) plan to enlist their physicians to help interpret and make use of the information-taking an early plunge into personalized genomic medicine, and dragging their physicians along. ${ }^{6,7}$

Determining what the couple believes they will gain from obtaining genomic information will help the neurologist address their hopes and questions. While some early uses of genomic information show promise and enjoy much attention in the media, many spotlighted advances are not ready for widespread application. ${ }^{1,8}$ The neurologist may need to counter current media hype that personalized genomic medicine for all has arrived, as well as caution against relying too much on patient testimonials published on direct-to-consumer Web sites. Although there is much hope that genomic information will contribute someday to risk assessment for stroke and other vascular diseases, evidence suggests that it currently adds little to risk assessment using traditional risk factors. ${ }^{5,9}$ Moreover, for race and ethnic groups not wellrepresented in genomic studies to date, the potential for relevant information drops exponentially. ${ }^{1,8,10}$ For example, the widely heralded study finding genetic risk associations for migraine included only women with verified European ancestry and thus the findings may not apply to this patient. ${ }^{11}$

This does not mean, however, that genomic information carries no clinical utility, but rather that its utility varies for different clinical decisions (table 2 for definitions of clinical utility, clinical validity, and analytic validity and their importance in determining whether genomic and genetic tests are ready for widespread clinical use). ${ }^{12}$ For example, genomic profiling may soon play a larger role in untangling diagnostic dilemmas as cases accumulate in which identification by genomic sequencing of rare allelic variants leads to successful diagnosis 
Table 2 Four main criteria developed by the ACCE Model Project of the CDC's Office of Public Health Genomics for evaluating whether a genetic or genomic test is ready for widespread clinical use ${ }^{a}$

Analytic validity of a genetic or genomic test refers to how accurately and reliably the test measures the genotype of interest

Clinical validity refers to how consistently and accurately the test detects or predicts the intermediate or final outcomes of interest

Clinical utility refers to how likely the test is to significantly improve patient outcomes

ELSI refers to the ethical, legal, and social implications that may arise in the context of using the test

a ACCE takes its name from the 4 main criteria for evaluating a genetic or genomic test: analytic validity, clinical validity, clinical utility, and associated ethical, legal, and social implications. Further description of the ACCE Model Project is available on the Centers for Disease Control and Prevention Web site (available at http://www.cdc.gov/genomics/gtesting/ACCE/index.htm; accessed June 24, 2011).

and treatment after sequentially testing candidate genes failed to help. ${ }^{13}$ Use of genomic results to guide medication selection and dosing-pharmacogenomics-long heralded as the likely first widespread application of the new genomics for screening, is beginning to show clinical utility. ${ }^{14}$ Of importance to neurologists, genetic testing may usefully guide prescribing of medications as far-ranging as clopidogrel, warfarin, statins, carbamazepine, and opiates. ${ }^{5,14}$ Some current recommendations carry particular importance for certain race and ethnic groups. For example, testing patients of Asian ancestry for HLA-B*1502, an allele occurring in high frequency in Asians, before starting carbamazepine may avert severe adverse reactions - a recommendation prominently displayed in a black box warning on the FDA-approved prescribing information.

In encouraging a realistic assessment of genomic profiling, the neurologist also should explain that, as with all screening tests, there are both false-positives and false-negatives. Current technology ranges widely in analytic validity (table 2), raising concerns over the accuracy of genomic sequences produced. Moreover, many reported associations between gene variants and health conditions have been difficult to replicate or have been refuted, casting doubt on the clinical validity of these reported associations. Experts estimate that even a genomic scan with full analytic validity could contribute to hundreds of potentially misleading clinical results. Such misleading results are not without risks of harm. False-positives carry the potential for psychological distress and expensive, unnecessary work-ups, while falsenegatives raise concerns that patients will be falsely reassured and fail to take important health-promoting steps they might otherwise take. ${ }^{8,15}$

Individualized assessments utilizing genomic findings must take into consideration other important information to place these findings into context—such as medical history, physical functioning, and laboratory investigations. ${ }^{1}$ Personalized genomic medicine requires more than individualized genomic information-it requires "personalization" in the traditional sense, the type of personalization that relies on good provider-patient relationships. While neurologists can supply the latter, they may be limited in how much they would be able to incorporate information from genomic profiling until user-friendly algorithms are developed that place genomic risk factors in relation to more traditional risk factors (see, for example, guides developed by the Clinical Pharmacogenetics Implementation Consortium of the Pharmacogenomics Research Network [CPIC] at http://pharmgkb.org/). Supporters of personalized genomic medicine must help develop these types of information systems and infrastructural support before the full promise of personalized genomic medicine as part of everyday clinical care can be realized. Until these are widely available, personal physicians may have little to offer in the actual interpretation of genomic information without the consultation or collaboration of a clinical geneticist. 


\section{Personalized genomic medicine requires more than individualized genomic information-it requires "personalization" in the traditional sense, the type of personalization that relies on good provider-patient relationships.}

While we have thus far generally discussed the couple as a unit, it is important to remember that one of the pair is the neurologist's long-term patient, but this is the first time her husband has sought the neurologist's counsel about matters relating to his own health. The case therefore raises questions of how the neurologist ought to handle his interests in obtaining genomic information, what duties might be owed to him during this conversation, and whether a doctor-patient relationship is established by how he is included in the discussion. One option is to treat the long-term patient's husband as interested family, with discussion focused on the patient herself. Much of the general advice would apply to him as well. However, the more the physician engages in discussing issues specific to his health, the more likely a doctor-patient relationship will be established. Entering into a doctor-patient relationship may be appropriate to assess his risk factors for stroke given the history of early stroke in his family, regardless of potential genomic findings. However, if a doctor-patient relationship is to be established, it should begin with a traditional initial evaluation, rather than through provision of advice about obtaining genomic information. This should be discussed openly, and early on in the appointment.

\section{Genomic information: Risks and burdens}

As described above, genomic profiling is a form of screening and carries risks associated with the potential for frequent false-positive and false-negative results. Obtaining genomic information also carries risks and burdens associated with more traditional forms of genetic testing that patients may not have considered, particularly if they have not been counseled about genetic testing or screening previously.

For example, in obtaining genomic profile results, patients risk the burden of getting information they would rather not have. After considerable thought, many individuals choose against genetic testing for conditions as varied as breast cancer, Huntington disease, and Alzheimer disease, exercising, in effect, their right not to know. ${ }^{12,16}$ Concern over the potential for psychological distress and other potential harms associated with receiving such information is especially acute when no effective preventive interventions exist. While experts debate the risk-benefit ratio of offering genetic testing when no effective preventive interventions exist, the advent of direct-to-consumer services giving people direct access nearly moots that discussion. Further, individuals focused on specific conditions may not have considered that obtaining a full genomic profile might reveal additional information about other conditions about which they would rather not know. ${ }^{4,8}$

Knowledge of personal genomic information may also bring unwanted responsibilities. Patients could potentially acquire knowledge of a genetic condition that they feel ethically obligated to share with others - their siblings and parents, their son and his fiancée, and perhaps more distant relatives - because this information may have considerable implications for others, whether related by love or genetics. Concerns about the preferences and rights of family members to know or not to know, as well as their need for appropriate genetic counseling, are magnified by the sheer volume of information potentially available through genomic profiles. ${ }^{4,15}$

Genetic information in the medical record, regardless of what it shows, also remains a concern, even with current legal protections in place. ${ }^{17}$ It is partly to avoid automatic place- 
ment in their medical records that some patients may choose to pursue genetic testing from direct-to-consumer services or from research studies rather than through their personal physicians. However, simply knowing genetic information places one at risk of needing to disclose it on some insurance application forms. While the federal Genetic Information Nondiscrimination Act of 2008 prohibits use of genetic information to discriminate in health insurance and employment, it does not address life, disability, or long-term care insurance. State laws may provide additional protections against genetic discrimination, but they also are less than comprehensive. Moreover, although legal protection against genetic discrimination reduces risk of its occurrence, it does not eliminate it.

If the neurologist does agree to review genomic information obtained either through a research study or a direct-to-consumer source with a patient, decisions will have to be made about whether to place a copy of the information into the patient's medical record and whether and how to document discussions about it. ${ }^{17}$ Some attention and care should be given to the decision to place genomic profile results in patient medical records. Many physicians will want to make these decisions together with patients. Ideally, these matters should be discussed before the genomic results arrive at the doctor's office.

\section{Participation in research as a way to obtain genomic information}

Finally, it is important to address certain issues that are particular to the research context in which patients hope to obtain their genomic profiles. If receipt of such information is an important motivating factor for their participation in the research study, it will be important to determine what they anticipate in terms of personalized genomic results and counseling and what the study actually intends. ${ }^{3,4,18}$ Enrolling in research under the mistaken belief that research is designed to offer personalized health benefit, a phenomenon called "therapeutic misconception," has been well-characterized in clinical trials research; whether it applies as frequently to genomic research studies is unknown. At the same time, even if patients understand that the study they are considering is not designed to benefit them, they may still overestimate the extent to which the researchers will be concerned with providing them some benefit from their contribution to the research. They should not enroll under a mistaken belief that they will obtain more than is being offered.

While research participants may want access to individualized genetic information and counseling, and indeed a nascent agreement is developing among researchers and other stakeholders that some ought to be given to participants, wide disagreement exists about how to strike the appropriate balance between respecting an individual's autonomy and preference to have the information and researchers' obligations of beneficence and nonmaleficence. $^{3,4,15,18,19}$ Added to the mix are important questions about the kind and amount of resources researchers should divert from research to providing individuals with results. Suggestions range from restricting information to that which is clinically relevant and actionable to giving participants access to any information they want; many who suggest providing individual information back to participants also suggest that participants should discuss results with their personal physicians or a genetics counselor, or both, who may or may not be provided by the research team. ${ }^{3,4}$ Due in part to the fact that these issues are unresolved, many researchers and institutional review boards currently insist that no genetic research results be returned to individual research participants, and specifically state in the consent form that none will be. ${ }^{3,4}$

Helping to clarify if indeed individualized genomic results will be returned as part of a research study, and if so, how, is an important task the neurologist can perform. This might simply involve looking over the consent form with patients or encouraging them to ask the researchers this specific question. If still not confident of the answer, or of a patient's ability to elicit it from the researchers on his or her own, the neurologist might agree to contact the researchers directly. This is a more complex and potentially time-consuming activity, which depends on the neurologist's relationship with the patient, and how much information the 
neurologist desires to have prior to deciding whether to agree to review genomic results from the study with the patient.

Knowing in what format genomic information will be provided is critical. Raw DNA code is difficult to interpret and potentially requires hundreds of hours from persons across a variety of expertise to usefully interpret whole genomic sequences. ${ }^{20}$ If researchers are only able to provide genomic information in this format, interpretation by the neurologist essentially would be impossible — a fact that should be made known to the couple. Nevertheless, even if such is the case, there still might be utility in patients' receiving and storing their genomic sequence themselves for future use. The idea that results from this "single test" could provide information about one's entire genome for use in all future health-related decision-making suggests an elegant efficiency many consider worth pursuing. ${ }^{1,5}$ Indeed, services like the monthly updated interpretations from a single submission of DNA provided by direct-toconsumer companies like 23andMe show glimpses of what the future holds in this regard (see https://www.23andme.com/).

Whether or not the research study the couple are considering joining will provide them with the genomic information they are expecting from their donation of a DNA sample, their ability to control whether others have access to this information may be limited. Current research practice is to store DNA samples in large biobanks accessible to multiple research teams; some direct-to-consumer companies also contribute samples to research. While sharing helps accrue the vast sample sizes necessary for sound research, it comes with increased risk of identification and loss of privacy for individuals whose DNA is represented. Genomic sequences, even when broken into small portions, carry the potential for individual identification. Indeed, some researchers emphasize in consent forms the impossibility of maintaining anonymity and genomic privacy even though privacy breaches are unlikely. ${ }^{21}$ These may be important considerations to some individuals in deciding whether to provide a DNA sample as part of research or a direct-to-consumer purchase.

Further, some individuals may dislike being unable to control the types of research for which their genomic information might be used in the future, for example mapping ancestry, comparing genetic predispositions to addiction among various ethnicities, and exploring genetic contributions to intelligence or criminality. Consent forms should contain information about potential future uses of participants' samples and genomic information. But patients should be made aware that in the absence of any stated limits on the consent form, current research regulations allow future use of stored deidentified samples and information by other researchers for studies not yet contemplated. For some, this lack of control over, and at times knowledge of, potential future uses figures in their decision-making about research enrollment, whether or not they are concerned about personal harms. Lack of existing legal protection against future use of stored samples and information currently engenders considerable debate, and research practices and regulations may change to provide more individual control. ${ }^{22,23}$

Aside from the potential to obtain genomic information, patients often report a desire to contribute to research. If no misunderstandings drive their desire to participate, physicians need not discourage participation, and at times may feel comfortable supporting it. Indeed, the type of personalized genomic medicine this couple hopes to pursue will only be possible if large numbers of individuals across multiple racial and ethnic groups enroll in studies needed to develop the requisite knowledge base.

\section{The future of genomic profiling}

Providing a DNA sample for genomic profiling will become a routine part of health care. Genomic sequences will be included in patients' electronic health records accompanied by regularly updated computerized interpretations to allow the full benefits of point-ofcontact personalized genomic medicine to be realized. Indeed, some prominent programs are studying the utility of doing this (see for example, Coriell Personalized Medicine Collaborative, http://cpmc.coriell.org/, accessed June 20, 2011). When and if inclusion of 
genomic profiles in electronic health records becomes automatic, such practices will ideally be accompanied by adequate protection against privacy incursions and discrimination.

\section{REFERENCES}

1. Secretary's Advisory Committee on Genetics, Health, and Society. Report on Genetics Education and Training: February 2011. Available at: http://oba.od.nih.gov/oba/SACGHS/reports/SACGHS_education_ report_2011.pdf. Accessed June 15, 2011.

2. Physicians as guardians of genetic knowledge. Lancet 2011;377:967.

3. Bookman EB, Langehorne AA, Eckfeldt JH, et al. Reporting genetic results in research studies: summary and recommendations of an NHLBI working group. Am J Med Genet A 2006;140:1033-1040.

4. Wolf SM, Lawrenz FP, Nelson CA, et al. Managing incidental findings in human subjects research: analysis and recommendations. J Law Med Ethics 2008;36:219-248.

5. Vance LM, Tekin D. Genomic medicine and neurology. Continuum Lifelong Learning Neurol 2011; 17:249-267.

6. Gollust SE, Gordon ES, Zayac C, et al. Motivations and perceptions of early adopters of personalized genomics: perspectives from research participants. Public Health Genomics Epub 2011 Jun 3.

7. Cherkas LF, Harris JM, Levinson E, Spector TD, Prainsack B. A survey of UK public interest in internet-based personal genome testing. PLoS One 2010;5:e13473.

8. Secretary's Advisory Committee on Genetics, Health, and Society. Report on Direct-to-Consumer Genetic Testing: April 2010. Available at: http://oba.od.nih.gov/oba/sacghs/reports/SACGHS_DTC_Report_2010. pdf. Accessed June 15, 2011.

9. Evaluation of Genomic Applications in Practice and Prevention (EGAPP) Working Group. Recommendations from the EGAPP Working Group: genomic profiling to assess cardiovascular risk to improve cardiovascular health. Genet Med 2010;12:839-843.

10. Ng PC, Murray SS, Levy S, Venter JC. An agenda for personalized medicine. Nature 2009;461:724-726.

11. Chasman DI, Schürks M, Anttila V, et al. Genome-wide association study reveals three susceptibility loci for common migraine in the general population. Nat Genet 2011;43:695-698.

12. Bunnik EM, Schermer MH, Janssens AC. Personal genome testing: test characteristics to clarify the discourse on ethical, legal and societal issues. BMC Med Ethics 2011;12:11.

13. Mayer AN, Dimmock DP, Arca MJ, et al. A timely arrival for genomic medicine. Genet Med 2011;13: $195-196$.

14. Secretary's Advisory Committee on Genetics, Health, and Society. Report on Realizing the Potential of Pharmacogenomics: Opportunities and Challenges: May 2008. Available at: http://oba.od.nih.gov/oba/ SACGHS/reports/SACGHS_PGx_report.pdf. Accessed June 15, 2011.

15. McGuire AL, Burke W. An unwelcome side effect of direct-to-consumer personal genome testing: raiding the medical commons. JAMA 2008;300:2669-2671.

16. Ensenauer RE, Michels VV, Reinke SS. Genetic testing: practical, ethical, and counseling considerations. Mayo Clin Proc 2005;80:63-73.

17. Klitzman R. Exclusion of genetic information from the medical record: ethical and medical dilemmas. JAMA 2010;304:1120-1121.

18. Beskow LM, Burke W. Offering individual genetic research results: context matters. Sci Transl Med 2010;2:38cm20.

19. Kohane IS, Mandl KD, Taylor PL, Holm IA, Nigrin DJ, Kunkel LM. Reestablishing the researcherpatient compact. Science 2007;316:836-837.

20. Ormond KE, Wheeler MT, Hudgins L, et al. Challenges in the clinical application of whole-genome sequencing. Lancet 2010;375:1749-1751.

21. Lunshof JE, Chadwick R, Vorhaus DB, Church GM. From genetic privacy to open consent. Nat Rev Genet 2008;9:406-411.

22. Bathe OF, McGuire AL. The ethical use of existing samples for genome research. Genet Med 2009;11:712715 .

23. Kohane IS, Altman RB. Health-information altruists: a potentially critical resource. N Engl J Med 2005;353:2074-2077.

\section{DISCLOSURES}

Dr. Chen serves on data safety monitoring boards for the NIH (NINDS, NHLBI, NIDA); receives publishing royalties for Professionalism in Tomorrow's Healthcare System: Towards Fulfilling the ACGME Requirements for Systems-Based Practice and Professionalism (University Publishing Group, 2005); and receives research support from the NIH (NHGRI, NIDA, NCI, NCRR). Dr. Shepherd reports no disclosures. 


\section{Related articles from other AAN physician and patient resources}

Neurology ${ }^{\circledR} \quad$ www.neurology.org

Transcobalamin 2 variant associated with poststroke homocysteine modifies recurrent stroke risk.

October 18, 2011;77:1543-1550.

Addressing the ethical, policy, and social challenges of preclinical Alzheimer disease. October 11, 2011;77:1487-1493.

Genomic biomarkers and cellular pathways of ischemic stroke by RNA gene expression profiling.

September 14, 2010;75:1009-1014.

Searching for oracles? Blood biomarkers in acute stroke.

August 4, 2009;73:393-399.

\section{Continuum ${ }^{\circledR} \quad \bullet \quad$ www.aan.com/go/elibrary/continuum}

Genomic medicine and neurology.

April 2011;17:249-267.

Primer on genetic counseling.

April 2011;17:268-279.

\section{Neurology Now ${ }^{\circledR} \quad$ www.neurologynow.org}

Neuropathy testing. January/February 2009;5:11.

Testing, testing.

November/December 2008;4:7.

Risky business.

November/December 2008;4:18-22.

Genetic testing and disease resources.

November/December 2008;4:38.

\section{Neurology Today ${ }^{\circledR} \quad$ - www.neurotodayonline.com}

DA warns companies about DTC genetics tests.

August 5, 2010;10:28.

Direct-to-consumer genetic tests for Alzheimer disease and more hit market: What to tell your patients.

April 3, 2008;8:22-23. 


\title{
Neurology ${ }^{\circ}$ Clinical Practice
}

\author{
Advising patients about obtaining genomic profiles \\ Donna T. Chen and Lois L. Shepherd \\ Neurol Clin Pract 2011;1;5-13 \\ DOI 10.1212/CPJ.0b013e31823cd13c
}

This information is current as of December 1, 2011

$\begin{array}{ll}\begin{array}{l}\text { Updated Information \& } \\ \text { Services }\end{array} & \begin{array}{l}\text { including high resolution figures, can be found at: } \\ \text { http://cp.neurology.org/content/1/1/5.full.html }\end{array} \\ \text { References } & \text { This article cites } 18 \text { articles, } 1 \text { of which you can access for } \\ \text { http://cp.neurology.org/content/1/1/5.full.html\#\#ref-list-1 } & \text { This article, along with others on similar topics, appears in } \\ \text { following collection(s): } & \text { All Ethics in Neurology/Legal issues } \\ \text { http://cp.neurology.org//cgi/collection/all_ethics_in_neur } & \text { sues } \\ \text { All Genetics } & \\ & \text { http://cp.neurology.org//cgi/collection/all_genetics } \\ & \text { Information about reproducing this article in parts (figures, } \\ & \text { its entirety can be found online at: } \\ \text { http://cp.neurology.org/misc/about.xhtml\#permissions } & \\ \text { Permissions \& Licensing } & \text { Information about ordering reprints can be found online: } \\ & \text { http://cp.neurology.org/misc/addir.xhtml\#reprintsus }\end{array}$

Updated Information \&

References

Subspecialty Collections
Information about ordering reprints can be found online:

t/cp.neurology.org/misc/addir.xhtmithreprintsus

Neurol Clin Pract is an official journal of the American Academy of Neurology. Published continuously since 2011, it is now a bimonthly with 6 issues per year. Copyright Copyright $₫ 2011$ by AAN Enterprises, Inc.. All rights reserved. Print ISSN: 2163-0402. Online ISSN: 2163-0933.

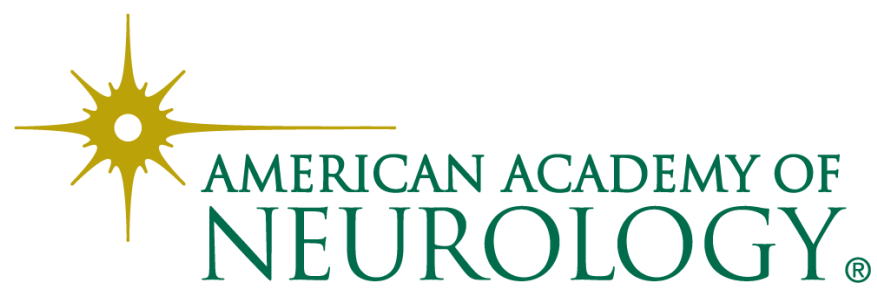

